\title{
Growth Differentiation Factor-15 Produces Analgesia by Inhibit- ing Tetrodotoxin-Resistant Nav1.8 Sodium Channel Activity in Rat Primary Sensory Neurons
}

\author{
Wei Lin ${ }^{1} \cdot$ Wen-Wen Zhang ${ }^{1} \cdot \operatorname{Ning}_{\mathrm{Lyu}^{1}} \cdot \mathrm{Hong}_{\mathrm{Cao}^{1}} \cdot$ Wen-Dong $\mathrm{Xu}^{1,2}$ • \\ Yu-Qiu Zhang ${ }^{1,3}$
}

Received: 21 December 2020/Accepted: 10 February 2021/Published online: 2 June 2021

(C) The Author(s) 2021

\begin{abstract}
Growth differentiation factor 15 (GDF-15) is a member of the transforming growth factor- $\beta$ superfamily. It is widely distributed in the central and peripheral nervous systems. Whether and how GDF-15 modulates nociceptive signaling remains unclear. Behaviorally, we found that peripheral GDF-15 significantly elevated nociceptive response thresholds to mechanical and thermal stimuli in naïve and arthritic rats. Electrophysiologically, we demonstrated that GDF-15 decreased the excitability of smalldiameter dorsal root ganglia (DRG) neurons. Furthermore, GDF-15 concentration-dependently suppressed tetrodotoxin-resistant sodium channel Nav1.8 currents, and shifted the steady-state inactivation curves of Nav1.8 in a hyperpolarizing direction. GDF-15 also reduced window currents and slowed down the recovery rate of Nav1.8 channels, suggesting that GDF-15 accelerated inactivation
\end{abstract}

Supplementary Information The online version contains supplementary material available at https://doi.org/10.1007/s12264-02100709-5.

Ning Lyu

ninglu@fudan.edu.cn

$\triangle$ Wen-Dong Xu

wendongxu@fudan.edu.cn

$\triangle$ Yu-Qiu Zhang

yuqiuzhang@fudan.edu.cn

1 Department of Translational Neuroscience, Jing'an District Centre Hospital of Shanghai, State Key Laboratory of Medical Neurobiology and Institutes of Brain Science, Fudan University, Shanghai 200032, China

2 Department of Hand Surgery, Huashan Hospital, Fudan University, Shanghai 200040, China

3 Department of Neurobiology, School of Basic Medical Sciences, Shanghai Medical College, Fudan University, Shanghai 200032, China and slowed recovery of the channel. Immunohistochemistry results showed that activin receptor-like kinase-2 (ALK2) was widely expressed in DRG medium- and smalldiameter neurons, and some of them were Nav1.8-positive. Blockade of ALK2 prevented the GDF-15-induced inhibition of Nav1.8 currents and nociceptive behaviors. Inhibition of PKA and ERK, but not PKC, blocked the inhibitory effect of GDF-15 on Nav1.8 currents. These results suggest a functional link between GDF-15 and Nav1.8 in DRG neurons via ALK2 receptors and PKA associated with MEK/ERK, which mediate the peripheral analgesia of GDF-15.

Keywords Growth differentiation factor-15 - Tetrodotoxin-resistant sodium channel Nav1.8 - Dorsal root ganglion $\cdot$ Whole-cell recording Activin receptor-like kinase-2 $\cdot$ Pain

\section{Introduction}

Growth differentiation factor-15 (GDF-15), also known as macrophage inhibitory cytokine-1, is a novel member of the bone morphogenetic protein (BMP)/transforming growth factor- $\beta$ (TGF- $\beta$ ) superfamily, which is widely distributed in the central and peripheral nervous systems [1]. It has been shown to play multiple roles in various physiological and pathological processes including growth differentiation, neuroprotection, inflammation, cancer, tissue injury, repair, and nerve regeneration [2-5]. In the central nervous system (CNS), GDF-15 protects nigrostriatal dopaminergic neurons in the 6-hydroxydopaminelesioned model and reduces losses of dopaminergic neurons $[6,7]$. In the periphery, GDF-15 maintains the survival of postnatal dorsal root ganglia (DRG) neurons and spinal, 
facial, as well as trigeminal motoneurons [8]. After peripheral nerve injury (e.g. mouse optic nerve or sciatic nerve injury), GDF-15 mRNA and protein are upregulated $[4,9]$ and local application of GDF-15 into the lesioned sciatic nerve promotes sensory regeneration [4]. As an antiinflammatory cytokine, GDF-15 has also been shown to have anti-inflammatory effects [10-15]. Despite the fact that GDF-15 has been implicated in peripheral nerve injury and inflammation, it is unclear whether it regulates nociceptive transmission.

Several members of the BMP/TGF- $\beta$ superfamily, such as Activins, BMPs, and TGF- $\beta$ s, are involved in the modulation of pain signaling [16-19]. A previous study from our lab showed that peripheral TGF- $\beta 1$ signaling contributes to bone cancer pain via regulating transient receptor potential vanilloid-1 (TRPV1) in primary sensory neurons [20]. In this study, we further investigated whether and how GDF-15 modulates peripheral nociceptive signaling in DRG neurons.

The effects on DRG ion channels may be an important mechanism of peripheral nociceptive modulation [21-24]. In neuropathic and inflammatory pain conditions, voltagegated $\mathrm{Na}^{+}$channels in nociceptive primary sensory neurons are involved in the development of peripheral hyperexcitability $[25,26]$. Among them, the tetrodotoxinresistant (TTX-R) $\mathrm{Na}^{+}$channel Nav1.8, mainly expressed by small- and medium-diameter DRG neurons [27, 28], substantially contributes to the upstroke of the action potential (AP) [29, 30]. Nav1.8-null mice show an increased threshold to noxious mechanical and thermal stimuli as well as delayed development of inflammatory pain [31]. Functional knockdown of Nav1.8 reduces the nociceptive hypersensitivity in neuropathic pain and inflammatory pain models $[25,32,33]$. In patients with painful small-fiber neuropathy, several Nav1.8 mutations have been identified, and some of these Nav1.8 mutations enhance the channel's response to depolarization and increase the excitability of DRG neurons [29, 34]. As an important target of pain relief, Nav1.8 is modulated by multiple drugs and molecules including pro- and antiinflammatory cytokines [35-37].

GDF-15 has been reported to increases the outward $\mathrm{K}^{+}$ and $\mathrm{Ca}^{2+}$ currents in rat cerebellar granule neurons by the Smad-independent Akt/mTOR and ERK signaling pathways $[38,39]$. Several second-messenger cascades including ERK, PKA, and PKC have been shown to regulate Nav1.8 channels [25, 40]. It is reasonable to hypothesize that GDF-15 may participate in pain modulation by regulating Nav1.8 channels to change DRG nociceptive neuronal excitability.

\section{Materials and Methods}

\section{Animals}

Adult female Wistar rats (120-180 g) were purchased from Shanghai Experimental Animal Center of the Chinese Academy of Sciences. The rats were housed under a 12/12 $\mathrm{h}$ light/dark cycle with a room temperature (RT) of $22 \pm$ $1{ }^{\circ} \mathrm{C}$ and received food and water ad libitum. All experimental procedures were approved by the Committee on the Use of Animal Experiments of Fudan University (permit No. SYXK 2009-0082) and followed the policies on the use of laboratory animals issued by the International Association for the Study of Pain (Washington D.C.). After the experiments, the rats were sacrificed by carbon dioxide inhalation. All the experiments including behavioral tests, electrophysiological recordings, and immunohistochemistry were performed by experimenters who were blinded to the treatments.

\section{Drugs and Chemicals}

GDF-15 was from Pepro Tech (120-28, Rocky Hill, NJ, USA). DMH-1, a selective ALK-2 receptor inhibitor, was from Selleck (S7146, Houston, TX, USA). All the other drugs were from Sigma-Aldrich (St. Louis, MO, USA). GDF-15 was dissolved in sterile $0.01 \mathrm{~mol} / \mathrm{L}$ PBS with $0.1 \%$ BSA and the other drugs were dissolved in normal saline. The drug dosages were selected based on our preliminary studies and previous reports. GDF-15 was applied to the chamber for $10-30 \mathrm{~min}$.

\section{Preparation of DRG Neurons and Patch-Clamp Recordings}

Acute isolation of DRG neurons was as described previously [20]. Briefly, rats were anesthetized with isoflurane and then rapidly decapitated. The L3-L6 DRGs were removed and immediately transferred to Dulbecco's modified Eagle's medium (DMEM; Invitrogen, Thermo Fisher Scientific, Carlsbad, CA, USA) on ice. The ganglia were minced and treated with collagenase (type IA, $2.67 \mathrm{mg} / \mathrm{mL}$, Millipore Sigma, Billerica, MA, USA) and trypsin (type I, $1 \mathrm{mg} / \mathrm{mL}$, Millipore Sigma) in DMEM saturated with $\mathrm{CO}_{2} /$ $\mathrm{O}_{2}$ mixed gas at $37^{\circ} \mathrm{C}$ for $30 \mathrm{~min}$. For electrophysiological recording, the isolated DRG neurons were plated onto glass coverslips in culture dishes and incubated with a standard external solution.

Whole-cell recordings were performed in DRG neurons with an Axonpatch 200B amplifier (Axon Instruments, USA) as described previously [20, 40]. Recording electrodes (ID. $0.86 \mathrm{~mm}$, OD. $1.5 \mathrm{~mm}$, BF 150-86-10, Sutter 
Instruments, USA) were pulled on a P-97 puller (Sutter instruments, USA) with a resistance of 3-5 M $\Omega$. The pipette solution contained (in mmol/L): $140 \mathrm{KCl}, 1 \mathrm{MgCl}_{2}$, $0.5 \mathrm{CaCl}_{2}$, 5 EGTA, 10 HEPES, $3 \mathrm{Na}_{2} \mathrm{ATP}, 0.2 \mathrm{NaGTP}$, $\mathrm{pH}$ was adjusted to 7.2 with $\mathrm{KOH}$. Seals $(>1 \mathrm{G} \Omega$ ) were established between the electrode and the cells. The cell membrane capacitance and series resistance were compensated $(>80 \%)$ after the whole-cell configuration was established. An online $\mathrm{p} / 4$ protocol was used for leak currents. Signals were filtered at $2 \mathrm{kHz}$ and sampled at 10 $\mathrm{kHz}$. For Nav1.8 current recordings, the external solution contained (in mmol/L): $32 \mathrm{NaCl}, 20$ TEA-Cl, 105 choline chloride, $1 \mathrm{MgCl}_{2}, 1 \mathrm{CaCl}_{2}, 1 \mathrm{CdCl}_{2}, 10$ HEPES, 10 glucose, and 0.0005 TTX, adjusted to $\mathrm{pH} 7.4$ with $\mathrm{NaOH}$. The pipette solution contained (in $\mathrm{mmol} / \mathrm{L}$ ): $140 \mathrm{CsF}, 1$ $\mathrm{MgCl}_{2}, 1$ EGTA, $5 \mathrm{Na}_{2}$ ATP, 10 HEPES, pH was adjusted to 7.2 with $\mathrm{CsOH}$. DRG neurons were held at $-60 \mathrm{mV}$ and Nav1.8 currents were elicited by depolarizing pulses to -10 $\mathrm{mV}$. The activation and inactivation properties of Nav1.8 currents were recorded with the appropriate voltage protocols. The voltage-clamp protocol $(50 \mathrm{~ms}$ depolarizing steps from $-50 \mathrm{mV}$ to $+5 \mathrm{mV}$ at $5-\mathrm{mV}$ increments) was used to determine the activation of Nav1.8 channels. The Boltzmann function of the form $G_{\mathrm{Na}} / G_{\mathrm{Namax}}=1 /\{1+\exp$ $\left.\left[\left(V_{\mathrm{m} 1 / 2}-V_{\mathrm{m}}\right) / k\right]\right\}$ was used to describe the voltage dependence of activation and half-activation potential. Steady-state inactivation of the Nav1.8 channel was determined at a series of membrane potentials from -60 $\mathrm{mV}$ to $-5 \mathrm{mV}$ at $5-\mathrm{mV}$ increments for $100 \mathrm{~ms}$ and a following $-10 \mathrm{mV}$ test potential. The Boltzmann function $I_{\mathrm{Na}} / I_{\text {Namax }}=1 /\left\{1+\exp \left[\left(V-V_{\mathrm{m} 1 / 2}\right) / k\right]\right\}$ was used to describe the steady-state inactivation curve, in which $I_{\text {Namax }}$ is the maximal peak current and $V$ is the prepulse membrane potential. All of the recordings were performed in small-diameter $(<25 \mu \mathrm{m})$ DRG neurons. pClamp 9.0 (Molecular Devices, Foster City, CA, USA) software was used during experiments and analysis.

\section{Immunohistochemistry}

Rats were deeply anesthetized with an overdose of urethane $(1.5 \mathrm{~g} / \mathrm{kg})$ and perfused with normal saline followed by $4 \%$ cold paraformaldehyde. L3-L6 DRGs were removed and postfixed in the same fixative for 4-6 h, and then immersed in a gradient of sucrose $(10 \%, 20 \%$, and $30 \%$ ) for $24-48 \mathrm{~h}$ at $4^{\circ} \mathrm{C}$ for cryoprotection. DRG sections $(14 \mu \mathrm{m})$ were cut on a Cryostat (CM1950, Leica, Wetzlar, Germany), mounted on silicone-wrapped slides, and stored at $-80^{\circ} \mathrm{C}$ until immunofluorescence labeling. Sections were incubated in blocking solution (10\% normal donkey serum in $0.01 \mathrm{~mol} / \mathrm{L}$ PBS with $0.3 \%$ Triton X-100) for $2 \mathrm{~h}$ at RT, then overnight at $4{ }^{\circ} \mathrm{C}$ with the following primary antibodies: goat anti-ALK2 (1:100, R\&D Systems, AF637,
Minneapolis, MN, USA), rabbit anti-Nav1.8 (1:200, ASC-016, Alomone, Jerusalem, Israel), rabbit anti-substance P (1:4000, Peninsula Labs, RIN7451, San Carlos, CA, USA), rabbit anti-CGRP, 1:20000, Peninsula Labs, IHC6006), mouse anti-peripherin (1:1000, Millipore, mab1527, Billerica, MA, USA). The sections were incubated with a mixture of Alexa Fluor 488- or Alexa Fluor 546-conjugated secondary antibodies (1:200, Invitrogen, A11055/A11036, Thermo Fisher Scientific, Waltham, MA, USA), or IB4-Alexa Fluor 488 (1:1000, Invitrogen, A21206, Thermo Fisher Scientific) for $2 \mathrm{~h}$ at RT. Omitting the primary antibodies and pre-absorption experiments were used to verify the specificity of immunostaining and primary antibodies. The stained sections were examined under a confocal laser-scanning microscope (FV1000, Olympus, Tokyo, Japan).

\section{Behavioral Experiments}

\section{von Frey Test for Mechanical Pain}

Rats were acclimated to the testing environment for 2-3 days before testing. Paw withdrawal thresholds (PWTs) in response to von Frey hairs (1-26 g, Stoelting Co., Wood Dale, IL, USA) were measured to determine the mechanical stimulation response threshold. Each rat was placed in a Plexiglas box $\left(10 \times 20 \times 20 \mathrm{~cm}^{3}\right)$ on an elevated metal mesh floor and habituated for $30 \mathrm{~min}$. A series of von Frey hair stimuli $(1.0,1.4,2,4,6,8,10,15$, and $26 \mathrm{~g})$ were delivered to the plantar surface of the central region of the hind paw. Each hair was applied 5 times at 15-s intervals and each time maintained for $2 \mathrm{~s}$. When the hind paw was withdrawal from a particular hair 3 out of the 5 consecutive applications, the value of the hair in grams was considered the PWT of the rat.

\section{Hargreaves Test for Thermal Pain}

The testing environment was the same as for the von Frey test. Paw withdrawal latencies (PWLs) in response to a radiant heat stimulus were measured to evaluate the thermal response threshold. Rats were placed in a Plexiglas box $\left(10 \times 20 \times 20 \mathrm{~cm}^{3}\right)$ on an elevated glass platform and acclimatized for $30 \mathrm{~min}$ before testing. A radiant heat source (IITC Life Science Instruments, Woodland Hills, CA, USA) was turned off when the rat lifted its foot. The time from the onset of radiant heat application to the withdrawal of the hind paw was defined as the PWL. The cut-off valve was set to $20 \mathrm{~s}$ to preventing tissue damage in the absence of a response. 


\section{Induction of Monoarthritis}

Complete Freund's adjuvant (CFA, $50 \mu \mathrm{L})$ was injected into the left ankle articular cavity to induce monoarthritis. The rat was briefly anesthetized with isoflurane and skin around the ankle was sterilized. A 30-gauge needle was inserted vertically to penetrate the skin and turned distally to insert into the articular cavity from the gap between the tibiofibular and tarsus bones until a distinct loss of resistance was felt. Sham arthritic rats were similarly injected with an equal volume of sterile normal saline.

\section{Statistical Analysis}

Data are presented as the mean \pm SEM and statistical analyses were performed using GraphPad Prism 7.0 software (San Diego, CA, USA). Statistical comparisons used Student's $t$-test (comparing 2 groups) or one-way or two-way RM ANOVA followed by the post hoc StudentNewman-Keuls test (comparing more than 2 groups). All the hypothesis testing was 2-tailed with $P<0.05$ considered statistically significant.

\section{Results}

\section{GDF-15 Decreases the Excitability of Nociceptive Primary Sensory Neurons and Suppresses Periph- eral Nociceptive Behaviors}

Previously, we investigated the effects of TGF- $\beta 1$ on the TRPV1 channel and neuronal excitability in primary sensory neurons, and its role in advanced bone cancer pain [20]. In this study, we further examined the effects of GDF-15, a novel member of the BMP/TGF $\beta$ superfamily, on the excitability of DRG neurons and peripheral nociceptive responses. Whole-cell current-clamp recordings showed that bath application of GDF-15 (1.2 nmol/L) significantly increased the rheobase from $30.56 \pm 2.76 \mathrm{pA}$ to $44.81 \pm 5.16 \mathrm{pA}$ after exposure to GDF-15 (Fig. 1A, B, Student's $t$-test, $t_{(61)}=2.6, P=0.012$ ). In addition, GDF-15 decreased the numbers of APs in response to $100 \mathrm{pA}, 500$ ms current injection (two-way repeated measures RM ANOVA, treatment: $F_{(1,33)}=20.74, P<0.0001$; Fig $1 \mathrm{C}$, D, S1A, B). Using 500-ms ramp current stimulation from 0 to $100 \mathrm{pA}(\Delta=0.2 \mathrm{pA} / \mathrm{ms})$, the latency to the first AP was prolonged and the numbers of APs were reduced (Fig. S1C-E). These data indicated that GDF-15 decreased the excitability of small-diameter DRG neurons. We also examined the effects of GDF-15 on the intrinsic membrane properties of DRG neurons. Analysis of the single AP evoked by step depolarization current stimulation showed that GDF-15-treated neurons had a more depolarized phase-plot curve and AP threshold than vehicle-treated neurons (Fig. 1E, F). No significant differences in resting membrane potential, AP amplitude, half-width, and afterhyperpolarization potential were identified between GDF15 and control groups (Fig. S1F-I).

The inhibitory effect of GDF-15 on the excitability of small-diameter DRG neurons suggests that peripheral GDF-15 is involved in nociception. Behavioral tests showed that intraplantar injection of GDF-15 $(1 \mu \mathrm{g})$ significantly inhibited the responses of rats to noxious thermal and von Frey mechanical stimuli. The analgesic effect was detected at 15 min after GDF-15 injection (Fig. $1 \mathrm{G}, \mathrm{H}$, two-way RM ANOVA, PWL: $F_{(1,13)}=16.54$, $P=0.0002$; PWT: $\left.F_{(1,13)}=10.43, P=0.003\right)$. Considering that previous studies have shown the involvement of GDF15 in arthritis in both humans and rodents [41, 42], we also examined the effect of GDF-15 on CFA-induced arthritic pain. Intra-ankle articular injection of CFA caused joint edema, erythema, and behavioral hypersensitivity (Fig. S2A-C). Intraplantar injection of GDF-15 inhibited the arthritis-induced thermal hyperalgesia and mechanical allodynia (Fig. 1, J, two-way RM ANOVA, PWL: $F_{(1,10)}=$ 4.47, $P=0.04$; PWT: $\left.F_{(1,13)}=4.25, P=0.046\right)$. Given that GDF-15 elevated the basal pain response thresholds in normal rats, we further examined the effect of blocking endogenous GDF-15 by neutralizing antibody on nociceptive responses. Intraplantar injection of GDF-15 antibody (GDF-15 Ab, $25 \mu \mathrm{g}$ ) produced mechanical allodynia and thermal hyperalgesia at 0.5 and $1 \mathrm{~h}$, suggesting that GDF15 also acts as an endogenous analgesic molecule (Fig. S2D, E).

\section{GDF-15 Suppresses Nav1.8 Currents in Small-Di- ameter DRG Neurons}

Nav1.8 makes a major contribution to the upstroke of APs in small-diameter DRG neurons [43]. Therefore, the modulation of this channel by GDF-15 may be involved in its effect on the excitability of DRG neurons. In the presence of TTX $(500 \mathrm{nmol} / \mathrm{L})$, TTX-R Na${ }^{+}$currents were recorded in most (approximately 75\%) of the smalldiameter $(<25 \mu \mathrm{m})$ DRG neurons. As in our previous report, Nav1.9 currents were inhibited when the membrane potential was held at $-60 \mathrm{mV}$ [40]. Nav1.8 currents were recorded in voltage-clamp mode (Fig. 2A). According to the I-V curve of the Nav1.8 channel (Fig. 2B), we selected $-10 \mathrm{mV}$ to evoke Nav1.8 currents. To test the effect of GDF-15 on Nav1.8 currents, acutely isolated DRG neurons were incubated with different doses of GDF-15, and Nav1.8 currents were recorded at 10, 20, and $30 \mathrm{~min}$. As shown in Fig. 2C-F, Nav1.8 currents were significantly decreased at 20 and $30 \mathrm{~min}$ after $1.2 \mathrm{nmol} / \mathrm{L}$ GDF-15. The $\mathrm{ED}_{50}$ was calculated to be $1.23 \mathrm{nmol} / \mathrm{L}$. To eliminate the 

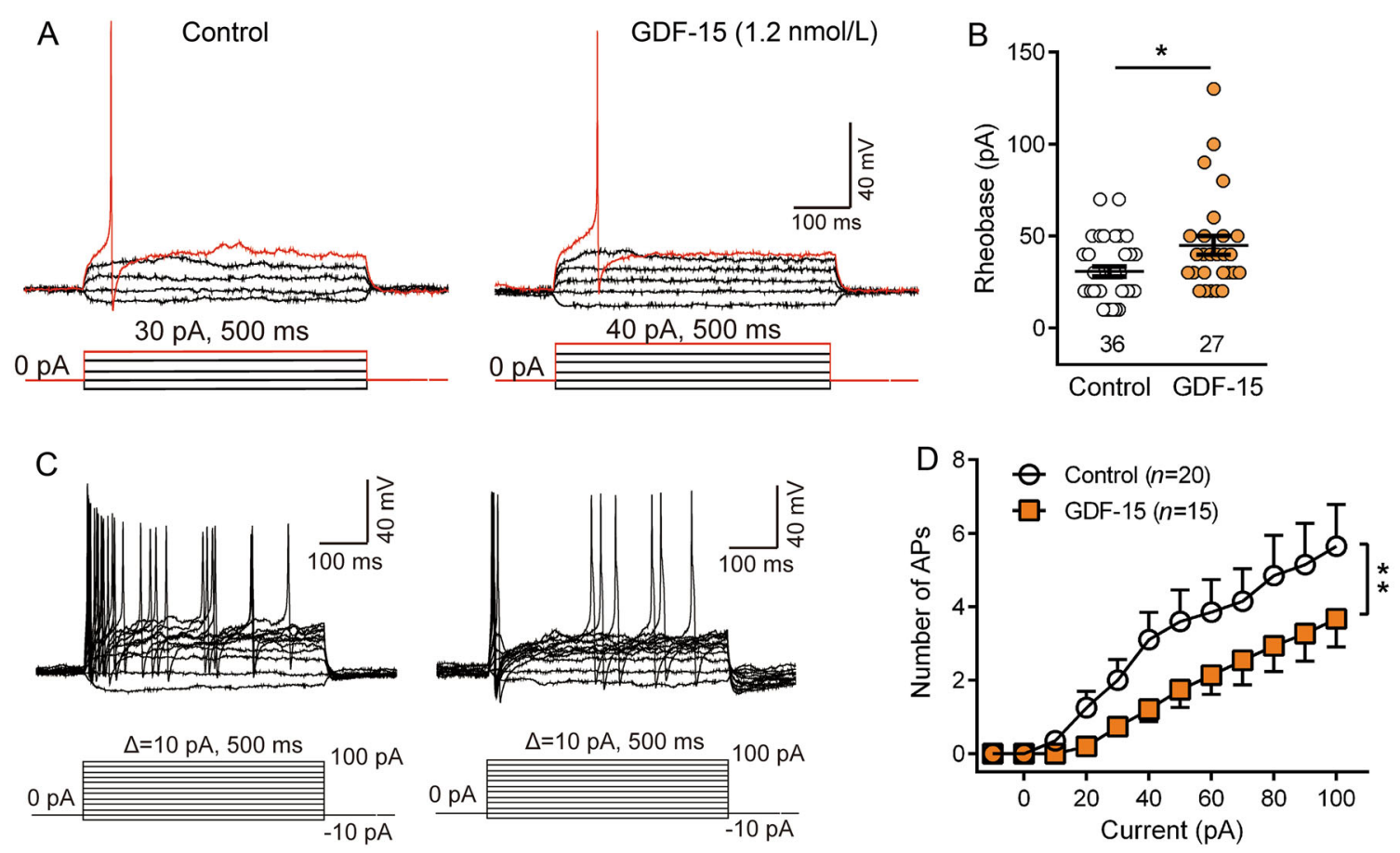
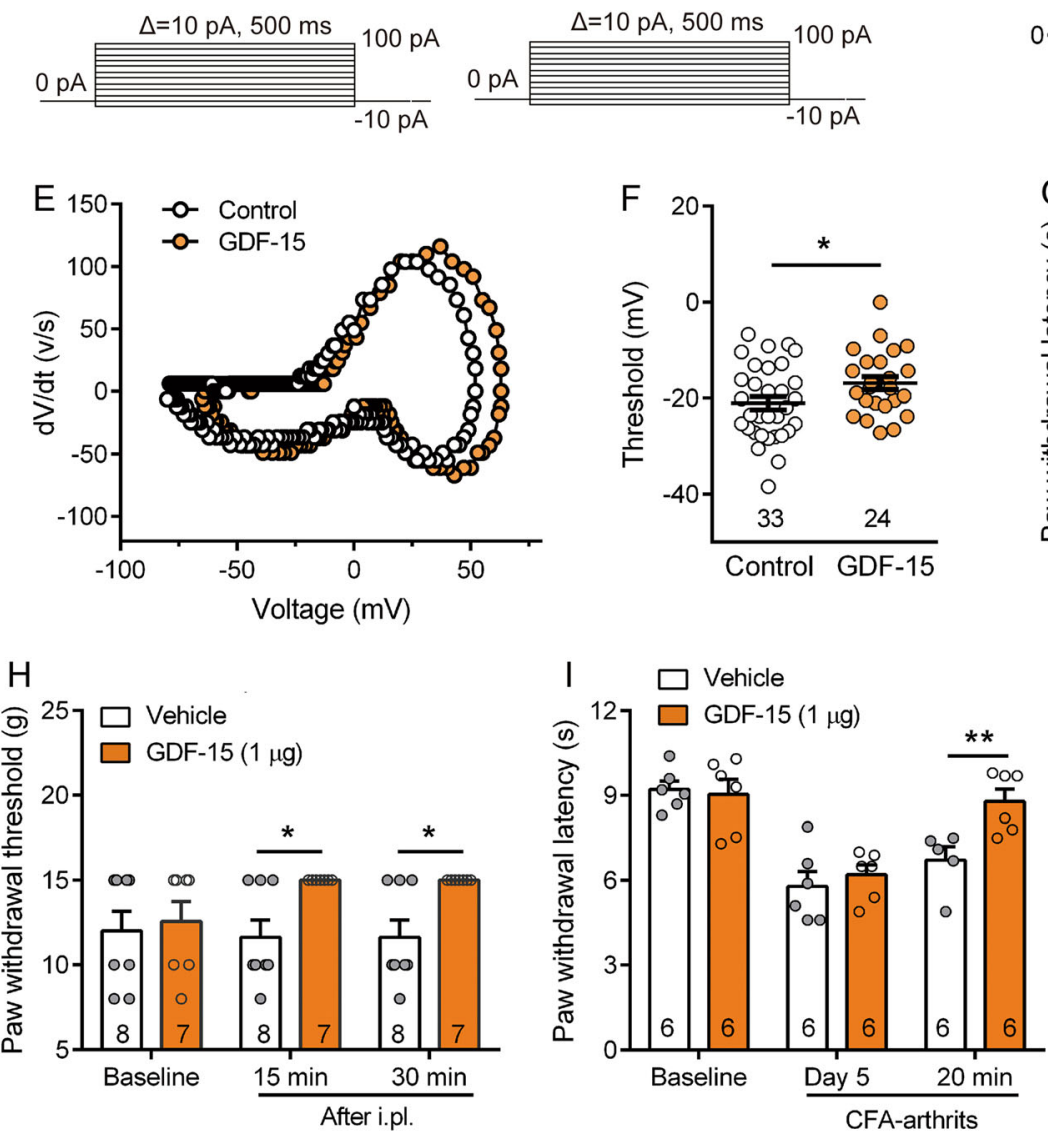

Fig. 1 GDF-15 decreases the excitability of nociceptive primary sensory neurons and inhibits nociceptive behaviors. A. In currentclamp model, the depolarizing current pulse requires to evoke an action potential (AP) in control and GDF-15 (1.2 nmol/L)-treated small-diameter DRG neurons. B. GDF-15 reduces the amount of current required to evoke an AP ( ${ }^{*} P<0.05$, Student's $t$-test). C. Examples of the AP responses to depolarizing current steps recorded from control and GDF-15 (1.2 nmol/L)-treated small-diameter DRG neurons. D. GDF-15 decreases the number of AP discharges in response to $100 \mathrm{pA}, 500 \mathrm{~ms}$ current injection ( $* * P<0.01$, two-way RM ANOVA). E. Phase plots of the APs from control and GDF-15 (1.2 nmol/L)-treated small-diameter DRG neurons. F. GDF-15 elevates the AP thresholds of small-diameter DRG neurons (*P<0.05, Student's $t$-test). G-J. Intraplantar injection of GDF-15 $(1 \mu \mathrm{g})$ increased the paw withdrawal latencies to noxious thermal stimulation ( $\mathbf{G}$ and $\mathbf{I})$ and paw withdrawal thresholds to von Frey mechanical stimulation $(\mathbf{H}$ and $\mathbf{J})$ in naïve $(\mathbf{G}$ and $\mathbf{H})$ and CFAarthritic rats (I and $\mathbf{J})(* P<0.05 ; * * P<0.01$, two-way RM ANOVA). 

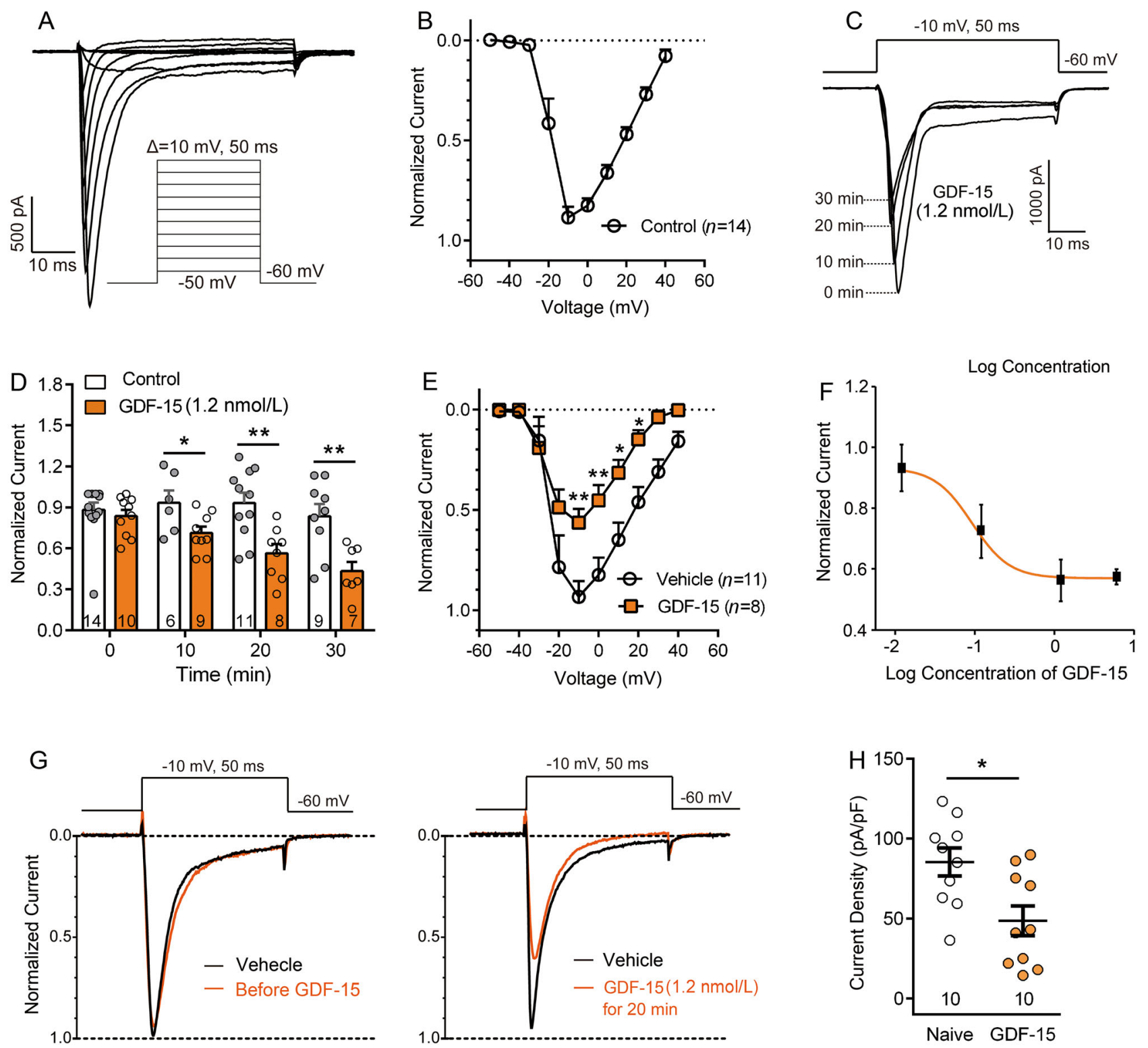

Fig. 2 GDF-15 inhibits Nav1.8 currents in small-diameter DRG neurons. A. Isolation of TTX-resistant Nav1.8 currents in the presence of $500 \mathrm{nmol} / \mathrm{L}$ TTX. Cells were depolarized to a variety of potentials $(-50 \mathrm{mV}$ to $+40 \mathrm{mV})$ from a holding potential of -60 $\mathrm{mV}$, to elicit Nav1.8 currents. B. I-V curve of Nav1.8 currents. $\mathbf{C}$ and D. Nav1.8 currents are reduced following incubation with GDF-15 for 10,20 , and $30 \min (* P<0.05$; $* * P<0.01$, two-way ANOVA). E. I-V curves of Nav1.8 currents of vehicle- and GDF-15-treated cells for 20

impact of cell size on the amplitude of currents, we also analyzed the current density of Nav1.8 channels. Incubation of GDF-15 $(1.2 \mathrm{nmol} / \mathrm{L})$ for $20 \mathrm{~min}$ significantly reduced the current density of Nav1.8 channels in DRG neurons either from naïve or arthritic rats (Student's $t$-test, $t_{(18)}=2.91, P=0.01$, Fig. 2G, H, S2D, E). $\min (* P<0.05 ; * * P<0.01$, two-way RM ANOVA). F. Dose-effect curve of GDF-15-induced inhibition of Nav1.8 currents elicited by a single pulse of $-10 \mathrm{mV}$. G. Typical traces illustrating the Nav1.8 currents elicited by a single pulse of $-10 \mathrm{mV}$ in small-diameter DRG neurons recorded pre- and post-GDF-15 $(1.2 \mathrm{nmol} / \mathrm{L})$ incubation for $20 \mathrm{~min}$. H. Nav1.8 currents density is decreased by GDF-15 (1.2 $\mathrm{nmol} / \mathrm{L})$ incubation for $20 \min (* P<0.05$. Student's $t$-test).

\section{Effect of GDF-15 on Kinetic Properties of Nav1.8 Channels}

To further understand the effect of GDF-15 on the gating kinetics of Nav1.8 channels, we analyzed their steady-state activation and steady-state inactivation properties. As shown in Fig. 3, no shift in the voltage-dependent activation curve was seen in the GDF-15-treated group 

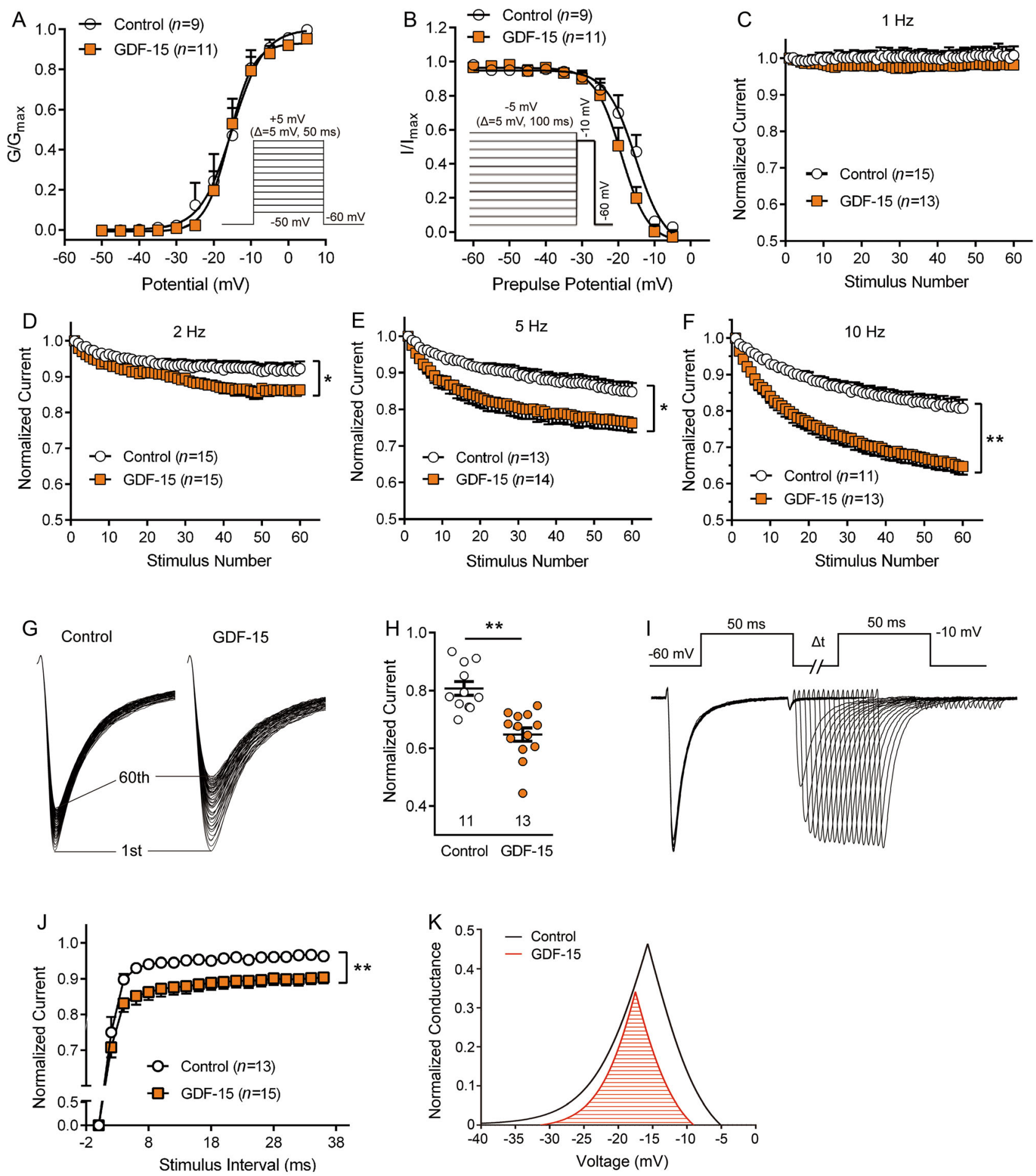

Fig. 3 Effects of GDF-15 on the kinetic properties of Nav1.8 channels. A. GDF-15 (1.2 nmol/L) does not shift the voltagedependent activation curve of Nav1.8 channels. B. GDF-15 left-shifts the steady-state inactivation curve of Nav1.8 channels in a hyperpolarizing direction. C-F. GDF-15 (1.2 nmol/L) exaggerates the frequency-dependent reduction of Nav1.8 currents with increasing stimulation frequency from 1 to $10 \mathrm{~Hz}(* P<0.05$; $* * P<0.01$, two- way RM ANOVA). $\mathbf{G}$ and $\mathbf{H}$. GDF-15 decreases the amplitude of Nav1.8 currents evoked by the $60^{\text {th }}$ pulse of $10 \mathrm{~Hz}$ stimulation (** $P<0.01$, Student's $t$-test). I and J. GDF-15 slows the recovery of Nav1.8 channels, using 18 paired-pulse with increasing interstimulus intervals. K. GDF-15 reduces the window currents of Nav1.8 channels, according to Boltzmann function fitting. 
compared with the control (Fig. 3A). The half-maximal activation potentials ( $V_{1 / 2}$ activation) were similar in the GDF-15 treatment and control groups $(-15.77 \pm 0.63 \mathrm{mV}$ vs $-15.1 \pm 1.05 \mathrm{mV}$, Student's $t$-test, $t_{(18)}=0.57, P=0.5$ ). A voltage protocol (pre-pulse potential: held at $-60 \mathrm{mV}$ ) differing from the activation curve of Nav1.8 channels, GDF-15 caused a left-shift toward the hyperpolarizing potential of the steady-state inactivation curve (Fig. 3B). The $V_{1 / 2}$ inactivation was $-15.36 \pm 0.95 \mathrm{mV}$ and $-19.11 \pm$ $0.65 \mathrm{mV}$ in the absence and presence of $1.2 \mathrm{nmol} / \mathrm{L}$ GDF15 , respectively (Student's $t$-test, $t_{(18)}=3.36, P=0.004$ ). We also analyzed the steady-state activation and inactivation properties of Nav1.8 channels in rats with CFAinduced arthritis and found a left-shifted activation curve compared to naive rats, suggesting that Nav1.8 channels were more sensitive under inflammatory conditions (Fig. S2H). Despite the change in the activation curve of Nav1.8 channels by CFA inflammation, GDF- 15 caused a left-shift toward the hyperpolarizing potential of the steady-state inactivation curve but had no influence on the steady-state activation curves in CFA inflammatory rats, similar to naive rats (Fig. S2H, I). The results suggest that GDF-15 exerted its inhibitory effect on Nav1.8 through fast inactivation of the channel.

Previous studies have shown that TTX-resistant $\mathrm{Na}^{+}$ channels are highly sensitive to repetitive depolarization [44]. When the interval between stimuli is not enough to restore the channels to the resting state, the number of opening channels will be less than that of the last stimulation. The shorter the interstimulus interval, the slower the recovery of $\mathrm{Na}^{+}$channel from inactivation, which is called frequency-dependent reduction [45]. Consistently, Nav1.8 currents showed a frequency-dependent reduction with increasing frequency of stimulation from 1 to $10 \mathrm{~Hz}$ in the vehicle control. In the presence of GDF-15, this frequency-dependent reduction became more pronounced, indicating a use-dependent decay with faster kinetics (Fig. 3C-F). The normalized amplitudes of currents evoked by the $60^{\text {th }}$ pulse at $10 \mathrm{~Hz}$ were significantly decreased in the presence of GDF-15 (Fig. 3G, 3H, Student's $t$-test, $\left.t_{(22)}=4.8, P<0.0001\right)$. We also analyzed the recovery curves of Nav1.8 channels. Channel recovery curves were recorded using 18 paired pulses with increasing interstimulus intervals, and then fitted with an exponential function $\left\{I / I_{\max }=A_{\text {fast }}\left[1-\exp \left(-t / t a u_{\text {fast }}\right)\right]+\right.$ $A_{\text {slow }}\left[1-\exp \left(-t / t_{\text {tau }}\right.\right.$ slow $\left.\left.)\right]\right\}$. As shown in Fig. 3I, J, GDF15 significantly slowed the recovery of Nav1.8 channels (two-way RM ANOVA, $F_{(1,26)}=8.85, P=0.006$ ), indicating that GDF-15 slowed the recovery rate of Nav1.8 channels. We also analyzed the window currents of Nav1.8 channels, which represented a small $\mathrm{Na}^{+}$current seen in a "window" of voltages where the activation and steadystate inactivation curves overlapped [46]. When a small fraction of Nav1.8 channels were likely to open at any moment, the larger the overlapping area, and the more opening channels. According to the Boltzmann function fitting, the window currents were reduced in the presence of GDF-15 (Fig. 3K). These data suggest that the inhibition of Nav1.8 currents by GDF-15 may be achieved by accelerating inactivation and slowing recovery of the channel.

\section{GDF-15 Reduces Nav1.8 Currents via ALK2}

ALK2, encoded by the ACVR1 gene, is a BMP type-I receptor subtype that mediates the actions of multiple BMP/TGF- $\beta$ superfamily molecules [47, 48]. Double immunostaining showed that ALK2 was widely distributed in DRG neurons, including medium-, small-diameter nociceptive (peripherin-positive), and large-diameter (peripherin-negative) neurons (Fig. 4A). Both peptidergic (SPand CGRP-positive) and non-peptidergic (IB4-positive) neurons expressed ALK2 (Fig. 4B-D). ALK2 was also colocalized with Nav1.8 channels in DRG neurons (Fig. 4E). To address whether the GDF-15-induced attenuation of Nav1.8 currents was mediated by ALK2, we examined the effect of dorsomorphin homolog 1 (DMH-1), an ALK2specific inhibitor of the inhibitory effects of GDF-15 on Nav 1.8 currents. Pretreatment of DRG neurons with 10 $\mu \mathrm{mol} / \mathrm{L}$ DMH-1 significantly blocked the GDF-15-induced suppression of Nav 1.8 currents (Fig. 5A-D, one-way ANOVA, $\left.F_{(3,30)}=4.5, P=0.01\right)$. We also tested the effects of DMH-1 on GDF-15-induced analgesia in CFA arthritic rats. As shown in Fig. 5E, 5F, intraplantar injection of DMH-1 $(20 \mu \mathrm{g} / 50 \mu \mathrm{L})$ completely blocked the analgesic effect of GDF-15 (one-way ANOVA, $F_{(3,26)}$ $=5.5, P=0.006$ for PWL; $F_{(3,26)}=3.9, P=0.02$ for PWT $)$.

\section{PKA and ERK Signaling Participate in GDF-15- induced Inhibition of Nav1.8 Channels}

Several non-Smad signaling pathways have been linked to rapid responses of multiple BMP/TGF- $\beta$ superfamily molecules. PKA, PKC, and ERK have been implicated in regulating the activity of Nav1.8 currents in DRG neurons [40, 49-51]. We, therefore, assessed whether PKA, PKC, or MEK/ERK were involved in the inhibition of Nav1.8 channels by GDF-15. Although the PKA inhibitor H89 (1 $\mu \mathrm{mol} / \mathrm{L})$ and the MEK/ERK inhibitor PD98059 $(10 \mu \mathrm{mol} /$ L) did not affect Nav1.8 currents per se, either of them significantly blocked the GDF-15-induced suppression of Nav1.8 currents (Fig. 5G-L, one-way ANOVA, $F_{(3,34)}=$ $4.4, P=0.01)$. In contrast, the PKC inhibitor BIM $(1 \mu \mathrm{mol} /$ L) did not block the inhibition of Nav1.8 currents by GDF15 (Fig. 5J-L). 

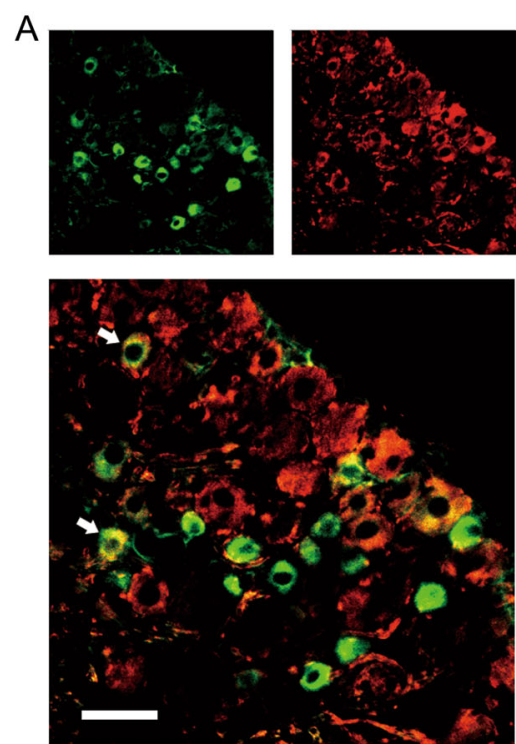

ALK2/peripherin

D
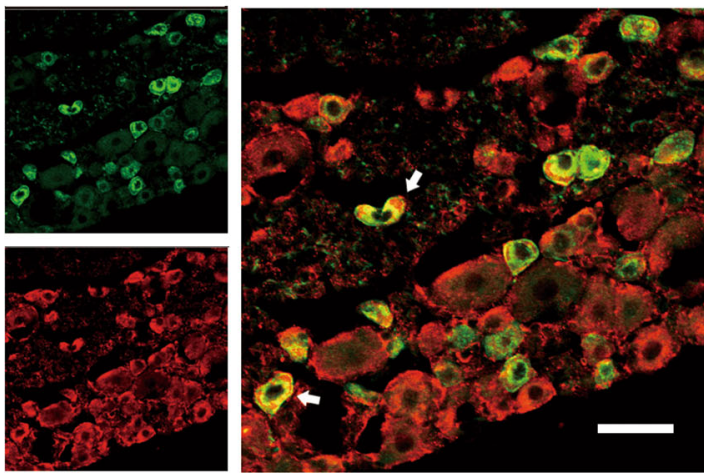

ALK2/IB4

Fig. 4 ALK2 expression in DRG neurons. A-D. Double immunofluorescence reveals the expression of ALK2 in peripherin- (A), substance P- (SP, B), calcitonin gene-related peptide- (CGRP, C),

\section{Discussion}

Previously, the BMP/TGF- $\beta$ superfamily members TGF$\beta 1$, Activins, and BMPs have been involved in chronic pain, including neuropathic, inflammatory, and cancer pain $[18,20,52]$. In the present study, we further provided insight into the analgesic effect of GDF-15, another member of the BMP/TGF- $\beta$ superfamily, at the peripheral level. Our results showed that peripheral application of GDF-15 significantly suppressed the behavioral responses to noxious thermal and mechanical stimuli in normal and CFA-arthritic rats. We also showed that GDF-15 dosedependently reduced Nav1.8 currents and decreased the excitability of small-diameter sensory neurons. This inhibition of Nav1.8 currents was blocked by a selective inhibitor of ALK2, suggesting that ALK2 is directly involved in GDF-15-induced changes in Nav1.8 activity.
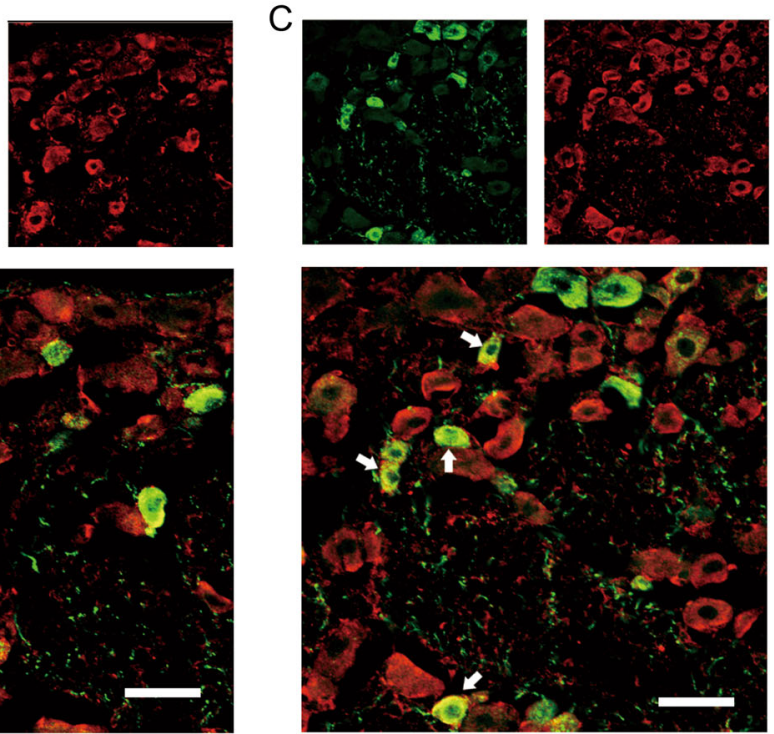

ALK2/CGRP

ALK2/SP
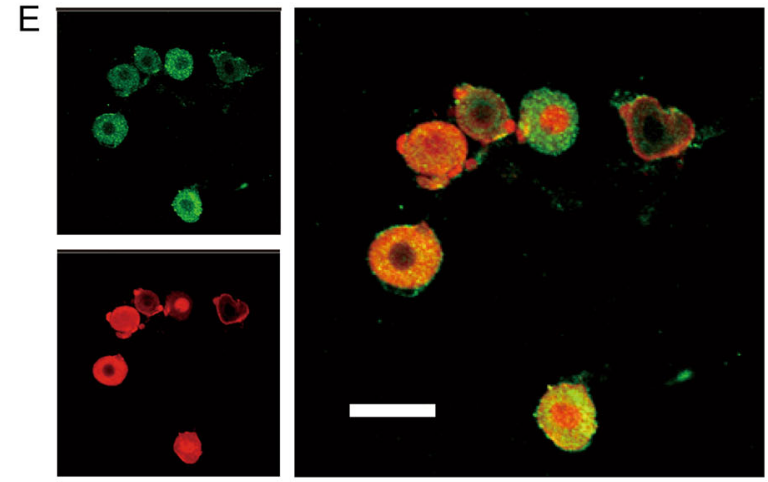

ALK2/Nav 1.8

and isolectin B4- (IB4, D) positive neurons in the DRG (scale bars, 50 $\mu \mathrm{m})$. E. Immunocytochemistry double staining of ALK2 and Nav1.8 in isolated DRG neurons (scale bar, $30 \mu \mathrm{m}$ ).

In addition, PKA and MEK/ERK signaling are responsible for the activation of Nav1.8 currents in response to GDF-15 in DRG neurons. These results suggest a peripheral mechanism of GDF-15 analgesia.

Among the pore-forming $\alpha$ subunits of Nav channels, Nav1.3, Nav1.6, Nav1.7, Nav1.8, and Nav1.9 $\mathrm{Na}^{+}$channels are present in DRG neurons and contribute to somatosensory signal transmission [25]. In particular, TTX-R Nav1.8 is expressed only in a subset of sensory neurons of which $>85 \%$ are nociceptors [24, 53]. Accumulating evidence points out that the Nav1.8 channel plays an important role in peripheral pain processing [54, 55]. Nociceptive signals evoke a dynamic change of Nav1.8 channels in the DRG: for example, paclitaxel-induced neuropathy [56], chronic compression of the DRG [26, 57], spinal nerve ligation, or local inflammation by the application of formalin, carrageenan, or CFA [58]. Either the 
A

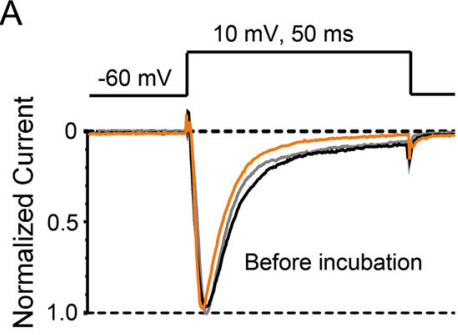

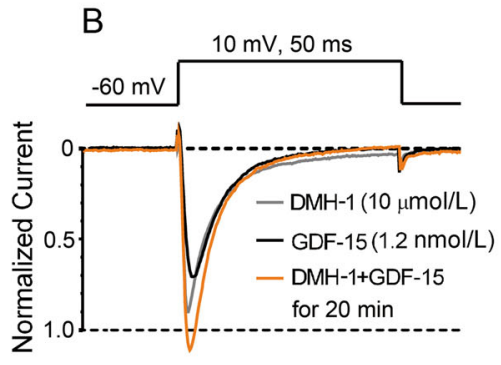

E
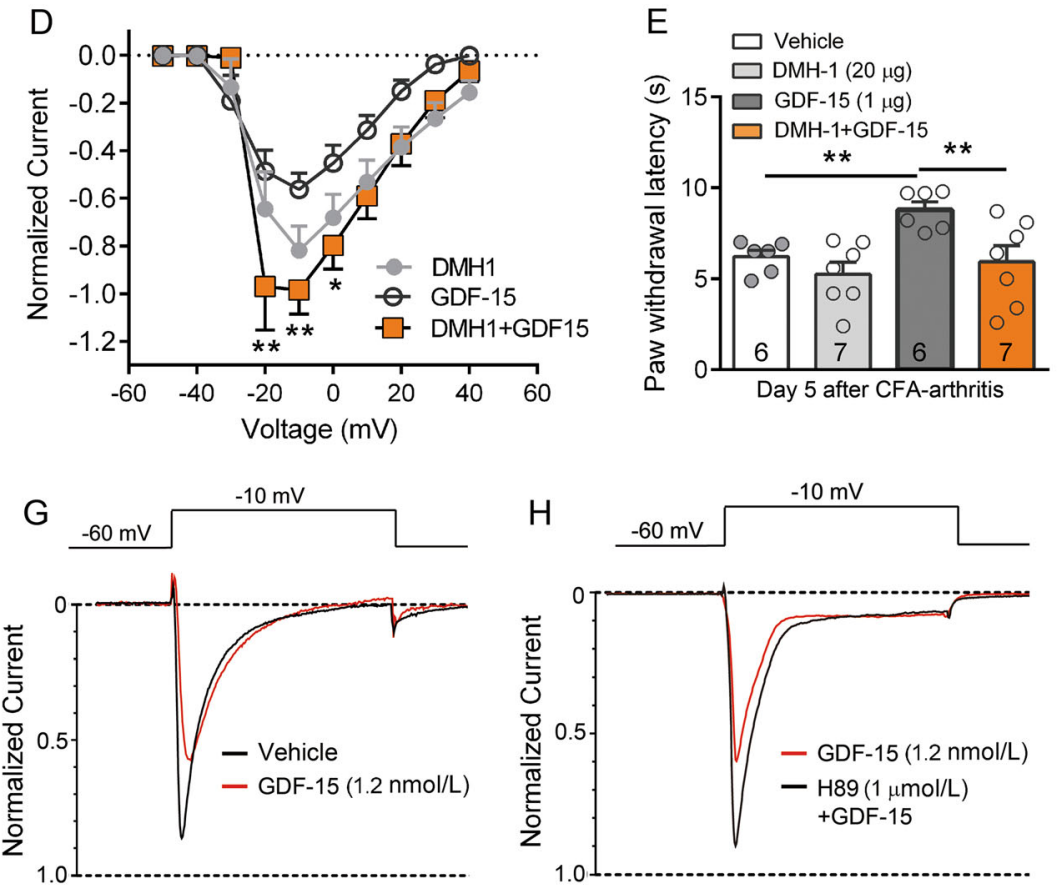

$\mathrm{H}$
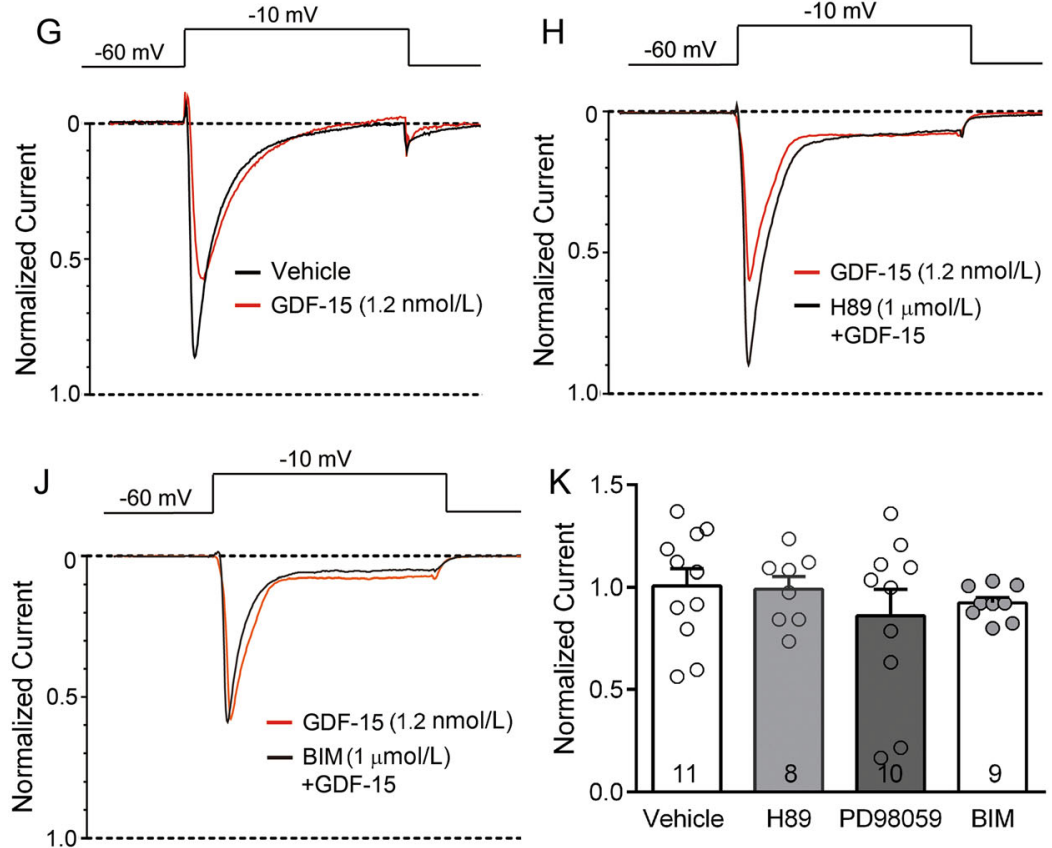
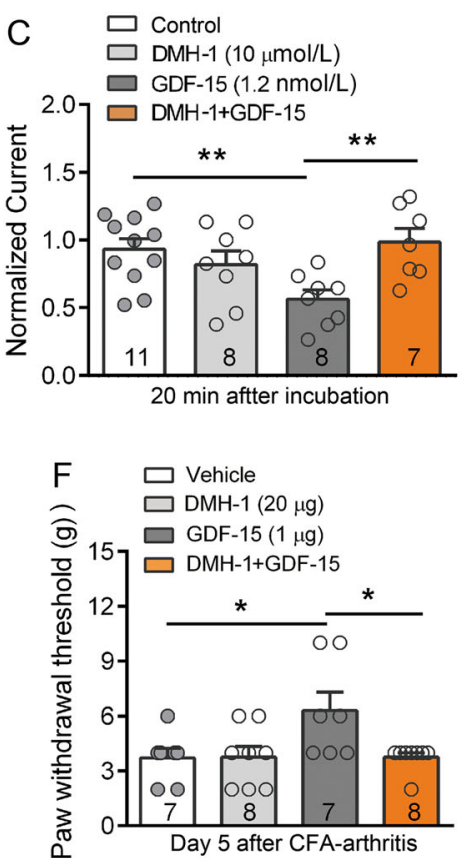
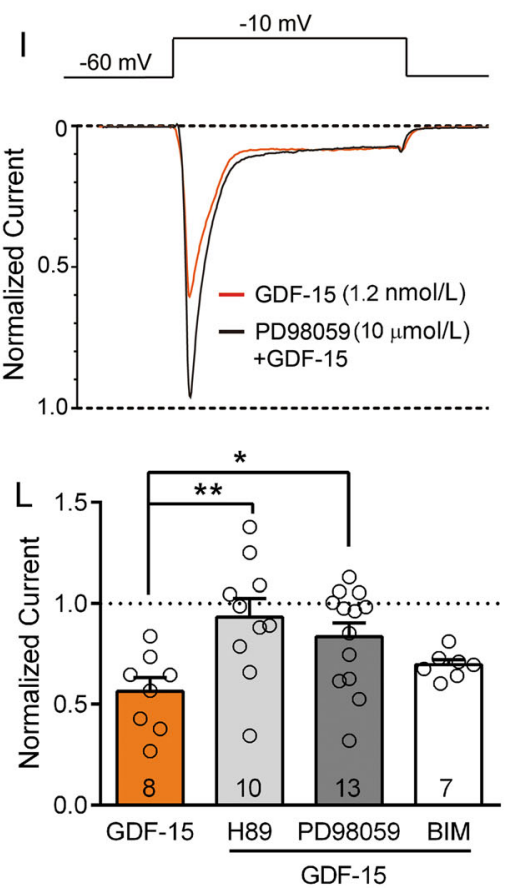

Fig. 5 GDF-15 reduces Nav1.8 currents via ALK2 and intracellular signaling of PKA and ERK in small-diameter DRG neurons. A-C. The ALK2-specific inhibitor DMH-1 blocks GDF-15-induced inhibition of Nav1.8 currents. DMH-1 per se does not affect Nav1.8 currents $(* * P<0.01$, one-way ANOVA). D. I-V curves of Nav1.8 currents of cells treated with DMH-1, GDF-15, and DMH-1+GDF-15 for $20 \mathrm{~min}$. E and F. Peripheral DMH-1 blocks GDF-15-induced inhibition of thermal hyperalgesia $(\mathbf{E})$ and mechanical allodynia (F) in CFA-arthritic rats. ( ${ }^{*} P<0.05,{ }^{*} P<0.01$, one-way ANOVA).
G-J. Typical traces illustrating that the PKA inhibitor H89 (H) and MEK/ERK inhibitor PD98059 (I), but not the PKC inhibitor BIM-1 (J) block the GDF-15-induced inhibition of Nav1.8 currents elicited by a single pulse of $-10 \mathrm{mV}$ in DRG neurons with GDF-15 (1.2 nmol/ L) incubation for $20 \mathrm{~min}$. K. H89, PD98059, or BIM per se do not change the Nav1.8 currents. L. Inhibition of Nav1.8 currents by GDF15 is blocked by $\mathrm{H} 89$ and PD98059, but not BIM $(* P<0.05$; $* * P<0.01$, one-way ANOVA). 
Fig. 6 Schematic showing how GDF-15 modulates peripheral nociceptive information. GDF15 inhibits Nav1.8 on nociceptors by membrane ALK2 and downstream intracellular signals, such as PKA and ERK, leading to a reduction in the excitability of DRG neurons and pain relief.

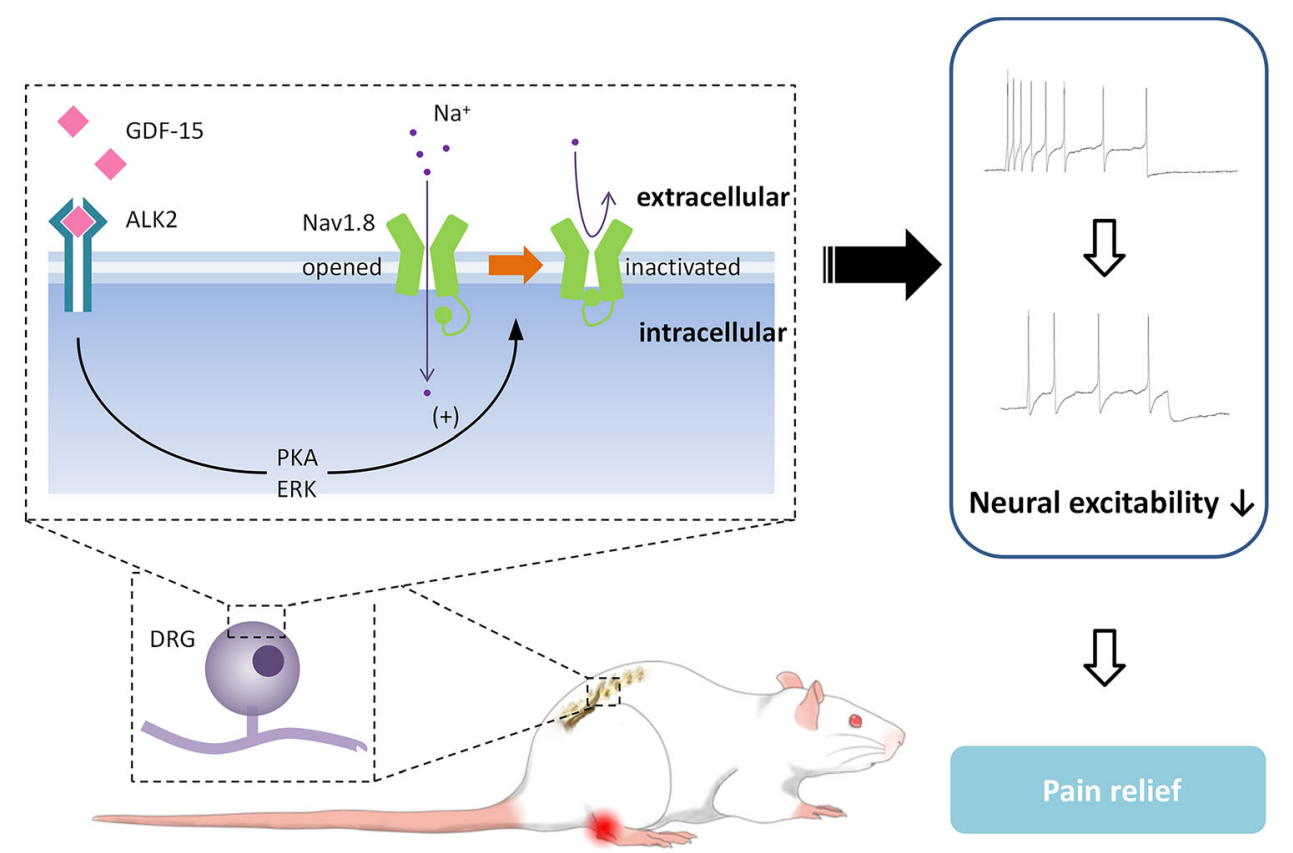

physiological or pathological pain is alleviated by Nav1.8 sodium channel blockers [58-60] or Nav1.8 knockout $[33,54]$. Human genetic evidence suggests that gain-offunction mutations in Nav1.8 channels contribute to painful peripheral neuropathy $[29,34]$.

Nav channels are necessary for the generation and conduction of APs, and Nav1.8 channels have been shown to contribute to the upstroke of the AP and support high repetitive firing rates [43]. Our data showed that GDF-15 significantly increased the AP threshold and decreased the frequency of AP discharges in small-diameter DRG neurons, suggesting that the decreased excitability by GDF-15 may be related to the regulation of Nav1.8 channels. Indeed, GDF-15 dose-dependently suppressed Nav1.8 currents and reduced window currents. Moreover, GDF-15 prompted a prominent hyperpolarizing shift in the inactivation but did not affect the activation. The frequency-dependent reduction was more pronounced by GDF-15, suggesting a significantly delayed recovery effect on $\mathrm{Na}^{+}$channels. This profile is quite consistent with the possibility that GDF-15 selectively affects the inactivated Nav1.8 channels.

The level of GDF-15 in the serum of rheumatic arthritis patients is higher than in healthy people [41, 42]. Exogenous GDF-15 decreases NF- $\mathrm{\kappa B}$ and downregulates interleukin-8 [13], suggesting the involvement of GDF-15 in the inflammatory disease process. In the current study, we further demonstrated that peripheral GDF-15 significantly suppressed nociceptive responses and relieved the mechanical allodynia and thermal hyperalgesia in normal and CFA-arthritic rats, corresponding to the inhibitory effect of
GDF-15 on the excitability of small-diameter DRG nociceptor neurons. Consistently, some other members of the BMP/TGF- $\beta$ superfamily, such as activins, BMPs, and TGF- $\beta$ s, have been shown to modulate nociceptive information [16-18, 52]. The inhibitory effects GDF-15 on nociceptive behaviors and Nav1.8 currents were markedly blocked by DMH-1, a specific inhibitor of ALK2, suggesting that ALK2 mediates the action of GDF-15. In support, ALK2 was widely expressed in DGR neurons, especially medium- and small-diameter nociceptive neurons, and co-localized with Nav1.8 channels.

ALK2 is a BMP type-I receptor subtype and plays an important role in the development of bones, muscles, brain, and other organs. ALK2 interacts with type II receptors to form transmembrane heterotetrameric receptor complexes and mediates the actions of multiple BMP/TGF- $\beta$ superfamily molecules $[47,48]$. Multiple intracellular signaling pathways are associated with the rapid actions of the TGF$\beta /$ BMP superfamily. It has been reported that GDF-15 activates BMP receptors and PI3K/Akt/mTOR and ERK signaling to rapidly regulate $\mathrm{K}^{+}$channels and $\mathrm{Ca}^{2+}$ channels $[38,39,61]$. In this study, we revealed that inhibition of PKA and ERK prevented GDF-15 from suppressing Nav1.8 currents. In support of this, it has also been reported that PKA [40, 62] and ERK [63, 64] modulate the Nav1.8 currents in small-diameter DRG neurons (Fig. 6).

Despite the fact that chronic pain is unevenly distributed between the sexes, occurring more frequently in women, and that clinical trials must incorporate women into the trial design $[65,66]$, current basic science research focuses 
primarily on male subjects. A recent study showed that patients with high GDF-15 levels have lower testosterone levels [67], suggesting an effect of male hormones on endogenous GDF-15 levels. Our findings demonstrated an analgesic effect of peripheral GDF-15 in female rats. Thus, future studies are warranted to investigate GDF-15 and its receptors signaling not only in different pain models but also in different sexes.

In summary, we found in the present study that GDF-15 dose-dependently suppressed Nav1.8 currents, aggravated the use-dependent reduction of Nav1.8 channels, attenuated the excitability of DRG neurons, and thus rapidly and effectively relieved pain. These findings provide an insight into the mechanisms underlying the analgesia of peripheral GDF-15. Despite the importance of the DRG, as a gatekeeper for the primary afferent nerves in acute and chronic pain development, the evidence for current therapeutic strategies is poor. This study might provide a potential neural target for an attempt to manage pain.

Acknowledgements This work was supported by the National Natural Science Foundation of China (82021002, 31771164, and $31930042)$, the National Key R\&D Program of China (2017YFB0403803), the Innovative Research Team of High-level Local Universities in Shanghai, Shanghai Municipal Science and Technology Major Project (2018SHZDZX01), and Zhang Jiang Laboratory.

Conflict of interest The authors declare that they have no conflict of interest.

Open Access This article is licensed under a Creative Commons Attribution 4.0 International License, which permits use, sharing, adaptation, distribution and reproduction in any medium or format, as long as you give appropriate credit to the original author(s) and the source, provide a link to the Creative Commons licence, and indicate if changes were made. The images or other third party material in this article are included in the article's Creative Commons licence, unless indicated otherwise in a credit line to the material. If material is not included in the article's Creative Commons licence and your intended use is not permitted by statutory regulation or exceeds the permitted use, you will need to obtain permission directly from the copyright holder. To view a copy of this licence, visit http://creativecommons. org/licenses/by/4.0/.

\section{References}

1. Strelau J, Bottner M, Lingor P, Suter-Crazzolara C, Galter D, Jaszai J, et al. GDF-15/MIC-1 a novel member of the TGF-beta superfamily. J Neural Transm Suppl 2000; 273-276.

2. Wischhusen J, Melero I, Fridman WH. Growth/differentiation factor-15 (GDF-15): from biomarker to novel targetable immune checkpoint. Front Immunol 2020, 11: 951.

3. Mimeault M, Batra SK. Divergent molecular mechanisms underlying the pleiotropic functions of macrophage inhibitory cytokine-1 in cancer. J Cell Physiol 2010, 224: 626-635.

4. Wang XL, Krebbers J, Charalambous P, Machado V, Schober A, Bosse F. Growth/differentiation factor-15 and its role in peripheral nervous system lesion and regeneration. Cell Tissue Res 2015, 362: 317-330.

5. Unsicker K, Spittau B, Krieglstein K. The multiple facets of the TGF- $\beta$ family cytokine growth/differentiation factor-15/macrophage inhibitory cytokine-1. Cytokine Growth Factor Rev 2013, 24: $373-384$.

6. Strelau J, Schober A, Sullivan A, Schilling L, Unsicker K. Growth/differentiation factor-15 (GDF-15), a novel member of the TGF-beta superfamily, promotes survival of lesioned mesencephalic dopaminergic neurons in vitro and in vivo and is induced in neurons following cortical lesioning. J Neural Transm Suppl 2003, 197-203.

7. Strelau J, Sullivan A, Böttner M, Lingor P, Falkenstein E, SuterCrazzolara C, et al. Growth/differentiation factor-15/macrophage inhibitory cytokine- 1 is a novel trophic factor for midbrain dopaminergic neurons in vivo. J Neurosci 2000, 20: 8597-8603.

8. Strelau J, Strzelczyk A, Rusu P, Bendner G, Wiese S, Diella F, et al. Progressive postnatal motoneuron loss in mice lacking GDF-15. J Neurosci 2009, 29: 13640-13648.

9. Charalambous P, Wang XL, Thanos S, Schober A, Unsicker K. Regulation and effects of GDF-15 in the retina following optic nerve crush. Cell Tissue Res 2013, 353: 1-8.

10. Zimmers TA, Jin XL, Hsiao EC, McGrath SA, Esquela AF, Koniaris LG. Growth differentiation factor-15/macrophage inhibitory cytokine-1 induction after kidney and lung injury. Shock 2005, 23: 543-548.

11. Vanhara P, Lincová E, Kozubík A, Jurdic P, Soucek K, Smarda J. Growth/differentiation factor-15 inhibits differentiation into osteoclasts-a novel factor involved in control of osteoclast differentiation. Differentiation 2009, 78: 213-222.

12. Breit SN, Johnen H, Cook AD, Tsai VW, Mohammad MG, Kuffner T, et al. The TGF- $\beta$ superfamily cytokine, MIC-1/ GDF15: a pleotrophic cytokine with roles in inflammation, cancer and metabolism. Growth Factors 2011, 29: 187-195.

13. Lambert JR, Whitson RJ, Iczkowski KA, La Rosa FG, Smith ML, Wilson RS, et al. Reduced expression of GDF-15 is associated with atrophic inflammatory lesions of the prostate. Prostate 2015, 75: 255-265.

14. Zhang M, Pan K, Liu Q, Zhou X, Jiang T, Li Y. Growth differentiation factor 15 may protect the myocardium from noreflow by inhibiting the inflammatory-like response that predominantly involves neutrophil infiltration. Mol Med Rep 2016, 13: 623-632.

15. Luan HH, Wang A, Hilliard BK, Carvalho F, Rosen CE, Ahasic AM, et al. GDF15 is an inflammation-induced central mediator of tissue tolerance. Cell 2019, 178: 1231-1244.

16. Zhu WG, Xu P, Cuascut FX, Hall AK, Oxford GS. Activin acutely sensitizes dorsal root ganglion neurons and induces hyperalgesia via PKC-mediated potentiation of transient receptor potential vanilloid I. J Neurosci 2007, 27: 13770-13780.

17. Xu P, van Slambrouck C, Berti-Mattera L, Hall AK. Activin induces tactile allodynia and increases calcitonin gene-related peptide after peripheral inflammation. J Neurosci 2005, 25: 9227-9235.

18. Tramullas M, Lantero A, Díaz A, Morchón N, Merino D, Villar A, et al. BAMBI (bone morphogenetic protein and activin membrane-bound inhibitor) reveals the involvement of the transforming growth factor-beta family in pain modulation. J Neurosci 2010, 30: 1502-1511.

19. Lantero A, Tramullas M, Díaz A, Hurlé MA. Transforming growth factor- $\beta$ in normal nociceptive processing and pathological pain models. Mol Neurobiol 2012, 45: 76-86.

20. Xu Q, Zhang XM, Duan KZ, Gu XY, Han M, Liu BL, et al. Peripheral TGF- $\beta 1$ signaling is a critical event in bone cancerinduced hyperalgesia in rodents. J Neurosci 2013, 33: 19099-19111. 
21. Shi YQ, Chen YY, Wang Y. Kir2.1 channel regulation of glycinergic transmission selectively contributes to dynamic mechanical allodynia in a mouse model of spared nerve injury. Neurosci Bull 2019, 35: 301-314.

22. Li Q, Lu J, Zhou XX, Chen XM, Su DS, Gu XY, et al. Highvoltage-activated calcium channel in the afferent pain pathway: An important target of pain therapies. Neurosci Bull 2019, 35: 1073-1084.

23. Urru M, Muzzi M, Coppi E, Ranieri G, Buonvicino D, Camaioni $\mathrm{E}$, et al. Dexpramipexole blocks Nav1.8 sodium channels and provides analgesia in multiple nociceptive and neuropathic pain models. Pain 2020, 161: 831-841.

24. Liu BL, Cao QL, Zhao X, Liu HZ, Zhang YQ. Inhibition of TRPV1 by SHP-1 in nociceptive primary sensory neurons is critical in PD-L1 analgesia. JCI Insight 2020, 5: 137386.

25. Dib-Hajj SD, Cummins TR, Black JA, Waxman SG. Sodium channels in normal and pathological pain. Annu Rev Neurosci 2010, 33: 325-347.

26. Fan N, Donnelly DF, LaMotte RH. Chronic compression of mouse dorsal root ganglion alters voltage-gated sodium and potassium currents in medium-sized dorsal root ganglion neurons. J Neurophysiol 2011, 106: 3067-3072.

27. Cummins TR, Sheets PL, Waxman SG. The roles of sodium channels in nociception: Implications for mechanisms of pain. Pain 2007, 131: 243-257.

28. Wang J, Ou SW, Wang YJ. Distribution and function of voltagegated sodium channels in the nervous system. Channels (Austin) 2017, 11: 534-554.

29. Faber CG, Lauria G, Merkies IS, Cheng XY, Han CY, Ahn HS, et al. Gain-of-function Nav1.8 mutations in painful neuropathy. Proc Natl Acad Sci U S A 2012, 109: 19444-19449.

30. Pryce KD, Powell R, Agwa D, Evely KM, Sheehan GD, Nip A, et al. Magi-1 scaffolds $\mathrm{Na}_{\mathrm{V}} 1.8$ and Slack $\mathrm{K}_{\mathrm{Na}}$ channels in dorsal root ganglion neurons regulating excitability and pain. FASEB $\mathrm{J}$ 2019, 33: 7315-7330.

31. Akopian AN, Souslova V, England S, Okuse K, Ogata N, Ure J, et al. The tetrodotoxin-resistant sodium channel SNS has a specialized function in pain pathways. Nat Neurosci 1999, 2: 541-548.

32. Ekberg J, Adams DJ. Neuronal voltage-gated sodium channel subtypes: key roles in inflammatory and neuropathic pain. Int $\mathbf{J}$ Biochem Cell Biol 2006, 38: 2005-2010.

33. Yu YQ, Zhao F, Guan SM, Chen J. Antisense-mediated knockdown of $\mathrm{Na}(\mathrm{V}) 1.8$, but not $\mathrm{Na}(\mathrm{V}) 1.9$, generates inhibitory effects on complete Freund's adjuvant-induced inflammatory pain in rat. PLoS One 2011, 6: e19865. https://doi.org/10.1371/ journal.pone.0019865.

34. Han CY, Vasylyev D, Macala LJ, Gerrits MM, Hoeijmakers JG, Bekelaar KJ, et al. The G1662S NaV1.8 mutation in small fibre neuropathy: impaired inactivation underlying DRG neuron hyperexcitability. J Neurol Neurosurg Psychiatry 2014, 85: 499-505.

35. Meng P, Huang HG, Wang G, Yang SL, Lu QM, Liu JZ, et al. A novel toxin from haplopelma lividum selectively inhibits the $\mathrm{Na}_{\mathrm{V}} 1.8$ channel and possesses potent analgesic efficacy. Toxins (Basel) 2016, 9: E7.

36. Zhang $\mathrm{F}$, Zhang $\mathrm{CX}, \mathrm{Xu} \mathrm{XX}$, Zhang YX, Gong $\mathrm{X}$, Yang ZQ, et al. Naja atra venom peptide reduces pain by selectively blocking the voltage-gated sodium channel Nav1.8. J Biol Chem 2019, 294: 7324-7334.

37. Amir R, Argoff CE, Bennett GJ, Cummins TR, Durieux ME, Gerner $\mathrm{P}$, et al. The role of sodium channels in chronic inflammatory and neuropathic pain. J Pain 2006, 7: S1-S29.

38. Wang CY, Huang AQ, Zhou MH, Mei YA. GDF15 regulates Kv2.1-mediated outward $\mathrm{K}^{+}$current through the Akt/mTOR signalling pathway in rat cerebellar granule cells. Biochem $\mathrm{J}$ 2014, 460: 35-47.

39. Lu JM, Wang CY, Hu CL, Fang YJ, Mei YN. GDF-15 enhances intracellular $\mathrm{Ca}^{2+}$ by increasing Cav1.3 expression in rat cerebellar granule neurons. Biochem J 2016, 473: 1895-1904.

40. Gu XY, Liu BL, Zang KK, Yang L, Xu H, Pan HL, et al. Dexmedetomidine inhibits Tetrodotoxin-resistant Nav1.8 sodium channel activity through Gi/o-dependent pathway in rat dorsal root ganglion neurons. Mol Brain 2015, 8: 15.

41. Brown DA, Moore J, Johnen H, Smeets TJ, Bauskin AR, Kuffner $\mathrm{T}$, et al. Serum macrophage inhibitory cytokine 1 in rheumatoid arthritis: a potential marker of erosive joint destruction. Arthritis Rheum 2007, 56: 753-764.

42. Tanrıkulu O, Sarıyıldı MA, Batmaz İ, Yazmalar L, Polat N, Kaplan I, et al. Serum GDF-15 level in rheumatoid arthritis: relationship with disease activity and subclinical atherosclerosis. Acta Reumatol Port 2017, 42: 66-72.

43. Renganathan M, Cummins TR, Waxman SG. Contribution of $\mathrm{Na}(\mathrm{v}) 1.8$ sodium channels to action potential electrogenesis in DRG neurons. J Neurophysiol 2001, 86: 629-640.

44. Vijayaragavan K, O'Leary ME, Chahine M. Gating properties of $\mathrm{Na}(\mathrm{v}) 1.7$ and $\mathrm{Na}(\mathrm{v}) 1.8$ peripheral nerve sodium channels. J Neurosci 2001, 21: 7909-7918.

45. Scholz A, Kuboyama N, Hempelmann G, Vogel W. Complex blockade of TTX-resistant $\mathrm{Na}+$ currents by lidocaine and bupivacaine reduce firing frequency in DRG neurons. J Neurophysiol 1998, 79: 1746-1754.

46. Frenz CT, Hansen A, Dupuis ND, Shultz N, Levinson SR, Finger $\mathrm{TE}$, et al. $\mathrm{Na}_{\mathrm{V}} 1.5$ sodium channel window currents contribute to spontaneous firing in olfactory sensory neurons. J Neurophysiol 2014, 112: 1091-1104.

47. Weiss A, Attisano L. The TGFbeta superfamily signaling pathway. Wiley Interdiscip Rev Dev Biol 2013, 2: 47-63.

48. Olsen OE, Sankar M, Elsaadi S, Hella H, Buene G, Darvekar SR, et al. BMPR2 inhibits activin and BMP signaling via wild-type ALK2. J Cell Sci 2018, 131: jcs213512.

49. Cang CL, Zhang H, Zhang YQ, Zhao ZQ. PKCepsilon-dependent potentiation of TTX-resistant Nav1.8 current by neurokinin-1 receptor activation in rat dorsal root ganglion neurons. Mol Pain 2009, 5: 33.

50. Liu C, Li Q, Su YY, Bao L. Prostaglandin E2 promotes Na1.8 trafficking via its intracellular RRR motif through the protein kinase A pathway. Traffic 2010, 11: 405-417.

51. Li Q, Qin L, Li JH. Enhancement by TNF- $\alpha$ of TTX-resistant $\mathrm{Na}_{\mathrm{V}}$ current in muscle sensory neurons after femoral artery occlusion. Am J Physiol Regul Integr Comp Physiol 2020, 318: R772-R780.

52. Lantero A, Tramullas M, Pílar-Cuellar F, Valdizán E, Santillán R, Roques BP, et al. TGF- $\beta$ and opioid receptor signaling crosstalk results in improvement of endogenous and exogenous opioid analgesia under pathological pain conditions. J Neurosci 2014, 34: 5385-5395.

53. Agarwal N, Offermanns S, Kuner R. Conditional gene deletion in primary nociceptive neurons of trigeminal ganglia and dorsal root ganglia. Genesis 2004, 38: 122-129.

54. Akopian AN, Sivilotti L, Wood JN. A tetrodotoxin-resistant voltage-gated sodium channel expressed by sensory neurons. Nature 1996, 379: 257-262.

55. Lai J, Porreca F, Hunter JC, Gold MS. Voltage-gated sodium channels and hyperalgesia. Annu Rev Pharmacol Toxicol 2004, 44: 371-397.

56. Zhang XL, Cao XY, Lai RC, Xie MX, Zeng WA. Puerarin relieves paclitaxel-induced neuropathic pain: the role of $\mathrm{Na}_{\mathrm{v}} 1.8 \quad \beta 1$ subunit of sensory neurons. Front Pharmacol 2018, 9: 1510 . 
57. Fan N, Sikand P, Donnelly DF, Ma C, Lamotte RH. Increased $\mathrm{Na}^{+}$ and $\mathrm{K}^{+}$currents in small mouse dorsal root ganglion neurons after ganglion compression. J Neurophysiol 2011, 106: 211-218.

58. Payne CE, Brown AR, Theile JW, Loucif AJ, Alexandrou AJ, Fuller MD, et al. A novel selective and orally bioavailable Nav 1.8 channel blocker, PF-01247324, attenuates nociception and sensory neuron excitability. $\mathrm{Br} \mathrm{J}$ Pharmacol 2015, 172: 2654-2670.

59. Liang JY, Liu XY, Pan MY, Dai W, Dong Z, Wang XL, et al. Blockade of Nav1.8 currents in nociceptive trigeminal neurons contributes to anti-trigeminovascular nociceptive effect of amitriptyline. Neuromolecular Med 2014, 16: 308-321.

60. Minett MS, Eijkelkamp N, Wood JN. Significant determinants of mouse pain behaviour. PLoS One 2014, 9: e104458. https://doi. org/10.1371/journal.pone.0104458.

61. Liu DD, Lu JM, Zhao QR, Hu CL, Mei YN. Growth differentiation factor-15 promotes glutamate release in medial prefrontal cortex of mice through upregulation of T-type calcium channels. Sci Rep 2016, 6: 28653.

62. Matsumoto S, Yoshida S, Ikeda M, Tanimoto T, Saiki C, Takeda $\mathrm{M}$, et al. Effect of 8-bromo-cAMP on the tetrodotoxin-resistant sodium (Nav 1.8) current in small-diameter nodose ganglion neurons. Neuropharmacology 2007, 52: 904-924.

63. Yang F, Sun W, Yang Y, Wang Y, Li CL, Fu H, et al. SDF1CXCR4 signaling contributes to persistent pain and hypersensitivity via regulating excitability of primary nociceptive neurons: Involvement of ERK-dependent Nav1.8 up-regulation. J Neuroinflammation 2015, 12: 219.

64. Chen OY, Donnelly CR, Ji RR. Regulation of pain by neuroimmune interactions between macrophages and nociceptor sensory neurons. Curr Opin Neurobiol 2020, 62: 17-25.

65. Mogil JS. Sex differences in pain and pain inhibition: Multiple explanations of a controversial phenomenon. Nat Rev Neurosci 2012, 13: 859-866.

66. Mogil JS, Chanda ML. The case for the inclusion of female subjects in basic science studies of pain. Pain 2005, 117: 1-5.

67. Liu H, Dai W, Cui Y, Lyu YN, Li Y. Potential associations of circulating growth differentiation factor-15 with sex hormones in male patients with coronary artery disease. Biomed Pharmacother 2019, 114: 108792 . 